\title{
Prognostic Factors Affecting Survival After Curative Resection in Patients with pT4aN0M0 Gastric Cancer
}

\author{
Zhang Bin ${ }^{1,2}$, Zhang Ye ${ }^{1,2}$, Zhang Zhen ${ }^{1}$ and Li Wei ${ }^{1,2 *}$ \\ ${ }^{1}$ Oncology Department of Traditional Chinese and Western Medicine, Affiliated Hospital of Jiangnan University, People's Republic of China \\ ${ }^{2}$ Jiangnan University, People's Republic of China \\ *Corresponding author: Li Wei, Oncology Department of Traditional Chinese and Western Medicine, Affiliated Hospital of Jiangnan \\ University, No.200, Huihe road, Wuxi, Jiangsu, People's Republic of China, People's Republic of China
}

\section{ARTICLE INFO}

Received: 慧 June 25, 2020

Published: 蔧 July 02, 2020

Citation: Zhang Bin, Zhang Ye, Zhang Zhen, Li Wei. Prognostic Factors Affecting Survival After Curative Resection in Patients with pT4aN0M0 Gastric Cancer. Biomed J Sci \& Tech Res 28(4)-2020. BJSTR. MS.ID.004683.

Keywords: Gastric Cancer; Prognostic Factors; pT4aN0M0; Curative Resection

\section{ABSTRACT}

Aim: The aim of this investigation was to evaluate the long-term survival and prognostic factors associated with pT4aNOM0 gastric cancer patients who underwent curative resection.

Methods: The clinicopathological data of 991 gastric cancer patients who underwent curative gastrostomy (R0 resection) and extended lymphadenectomy (D2 or D2+) in our hospital from December 2009 to June 2016 was retrospectively analyzed.

Results: In total, 84 pT4aN0M0 gastric cancer patients were recruited to the study. The median follow-up period of the 84 cases was 40 months. The 1, 3 and 5 -year overall survival rates were $83.9 \%, 67.0 \%$ and $39.2 \%$, respectively. Univariate analysis showed that higher preoperative level of CEA $(\mathrm{p}=0.011)$, poorly differentiated pathological classification $(\mathrm{p}=0.023)$, tumor with Borrmann type IV $(\mathrm{p}=0.005)$, without postoperative chemotherapy $(p=0.039)$, the presence of lymphatic and vascular invasion ( $p<0.001)$ were associated with impaired Overall Survival (OS). Multivariate analysis of the above variables revealed that the level of CEA $(p<0.001)$ and the presence of lymphatic invasion $(\mathrm{p}<0.001)$ were the only independent prognostic factors for OS.

Conclusion: Our study found that the higher preoperative serum level of CEA and the presence of lymphatic invasion were associated with an unfavorable OS for pT4aN0M0 gastric cancer patients. Such patients should be provide individual followup and adjuvant therapy postoperatively.

\section{Introduction}

Gastric cancer is still one of the most common tumors in the world, although shows decreasing trends in its incidence in recent years. Surgery is the main method to provide the opportunity for radical cure [1-4]. The presence of lymph node metastases and the depth of tumor invasion are most important predictors of postoperative outcome for gastric cancer patients without distant organ metastasis [5-6].For advanced gastric cancer, compared to those with nodal metastases, the patients with node-negative gastric cancer have better prognosis [7-8]. A significant positive correlation was found between $\mathrm{T}$ staging and $\mathrm{N}$ staging in gastric cancer patients. However, in some other cases, postoperative pathological results revealed nodal metastases still do not developed even when tumor cells invade the serosa [9-10]. For these patients, more attention should be paid on long-term survival and prognostic factors associated because of its unique biological characteristics. The aim of this investigation was to evaluate the long-term survival and prognostic factors associated with pT4a patients with node-negative gastric cancer who underwent curative resection. 


\section{Material and Methods}

\section{Patients}

The data of gastric cancer patients who underwent curative gastrostomy (R0 resection) in our hospital from December 2009 to June 2016 was retrospectively analyzed. The patients underwent D2 or D2+ lymph node dissection accordance with the Japanese Gastric Cancer Association Guidelines and postoperative pathological TNM staging diagnosed as pT4aN0M0 based on the seventh edition of the Union for International Cancer Control TNM Classification [11] were enrolled in this investigation. Exclusion criterias were as follows: (1) Patients with lymph node metastases and/ or distant metastases. (2) Patients underwent preoperative chemotherapy and/ or radiation therapy. (3) The number of lymph nodes dissection was less than 16. (4) Suffered from other synchronous primary tumors simultaneously. Lymph node metastasis status was pathological examined by routine method in this investigation.

\section{Date Collection}

This study was approved by the Regional Ethics Committee of our institution. We collected and analyzed the data of patients, including demographic features, preoperative laboratory examination, postoperative pathological finding, postoperative adjuvant therapy, and postoperative survival. Demographic data included age, gender and Body Mass Index (BMI). Preoperative laboratory examination results included the level of hemoglobin, albumin and platelet. Operation procedures included the type of gastrectomy (distal subtotal gastrectomy / total gastrectomy), operative time and intraoperative blood loss. Pathological findings included tumor size and location, distance of resection margin, the presence of lymphovascular invasion, histologic classification, and number of lymph node dissection. The size of tumor was calculated by longest diameter. The histologic classification types were divided into a highly/ moderately differentiated group and a poorly differentiated group based on World Health Organization Classification. The location of tumor was divided into L / M / U part according to the position of lesion center. The patients of this study were divided into a chemotherapy group and a non-chemotherapy group based on whether underwent postoperative adjuvant chemotherapy. The main postoperative adjuvant chemotherapy scheme included FOLFOX and SOX followed 7th NCCN guidelines for gastric cancer in this investigation. In this investigation we use Overall Survival (OS) to assessed postoperative outcomes which defined as the time from date of surgery to either date of death or date of last patient contact. Follow-up information was obtained from outpatient medical record, clinical visits, and telephone interviews.

\section{Statistical Analysis}

All statistical analyses were performed by SPSS 15.0. Survival curves were analyzed by using the Kaplan-Meier method, and the differences between subgroups were compared by means of the log-rank test. The independent prognostic factors identified by multivariate analysis by performed using the Cox proportional hazard regression model with a forward stepwise procedure. Values of $p<0.05$ were considered to be statistically significant.

\section{Results}

\section{Characteristics of Patients}

In total, clinicopathological data of 991 patients was analyzed and 84 patients were recruited to the study. The complete demographic details of 84 patients are summarized in (Table 1). The cases comprised 53 (63.1\%) males and 31 (36.9\%) females, and the mean age was $68.9 \pm 6.4$ years (range: 48 to 79 years); 40 patients underwent total gastrectomy and distal gastrectomy was executed in 44 patients. The size of tumor diameter was $4.5 \pm 2.1$ $\mathrm{cm}$ (range: 1.1 to $11.1 \mathrm{~cm}$ ). In 19 patients (22.6\%) tumor were located in the upper third of stomach (U) and middle third (M) in 32 patients (38.1\%), lower third (L) in 33 patients (39.3\%). Based on macroscopic type, Borrmann II in 32 patients (38.1\%), Borrmann III in 46 patients $(54.8 \%)$ and Borrmann IV in 6 patients $(7.1 \%)$, respectively. According to the postoperative histology, well and/ or moderately differentiated tumour were observed in 38 patients (45.2\%), and poorly differentiated and/or undifferentiated tumour were observed in the remaining 46 patients (54.8\%). In node-negative patients with gastric cancer, 44 (52.4\%) patients underwent postoperative chemotherapy, while 40 (47.6\%) did not. Table 1: Clinicopathological findings in 84 patients with pT4aN0M0 gastric cancer who underwent curative resection.

\begin{tabular}{|c|c|}
\hline Variables & Patients $(n=84)$ \\
\hline Mean age (years, mean $\pm S D$ ) & $68.9 \pm 6.4$ \\
\hline \multicolumn{2}{|l|}{ Sex $(\%)$} \\
\hline Male & $53(63.1)$ \\
\hline Female & $31(36.9)$ \\
\hline $\mathrm{BMI}($ mean $\pm \mathrm{SD})$ & $21.4 \pm 1.5$ \\
\hline Hemoglobin $(\mathrm{g} / \mathrm{L}$, mean \pm SD) & $107.2 \pm 22.3$ \\
\hline $\operatorname{Albumin}(\mathrm{g} / \mathrm{L}$, mean $\pm \mathrm{SD})$ & $35.0 \pm 3.5$ \\
\hline Platelet $\left(\times 10^{\wedge} 9 / \mathrm{L}\right.$, mean $\left.\pm \mathrm{SD}\right)$ & $207.8 \pm 56.4$ \\
\hline CEA (ng/ml, mean \pm SD) & $9.7 \pm 8.4$ \\
\hline Mean tumor size $(\mathrm{cm}$, mean $\pm \mathrm{SD})$ & $4.5 \pm 2.1$ \\
\hline \multicolumn{2}{|l|}{ Laparoscopic surgery (\%) } \\
\hline Yes & $73(86.9)$ \\
\hline NO & $11(13.1)$ \\
\hline \multicolumn{2}{|l|}{ Type of gastrectomy (\%) } \\
\hline Distal gastrectomy & $44(52.4)$ \\
\hline Total gastrectomy & $40(47.6)$ \\
\hline Number of lymph node dissection (mean \pm SD) & $25.4 \pm 7.3$ \\
\hline Operative time (min, mean $\pm \mathrm{SD})$ & $251 \pm 27.8$ \\
\hline Intraoperative blood loss (ml, mean \pm SD) & $87.5 \pm 82.5$ \\
\hline
\end{tabular}




\begin{tabular}{|c|c|}
\hline Distance of resection margin $(\mathrm{cm}$, mean $\pm \mathrm{SD})$ & \\
\hline Proximal margin & $5.9 \pm 0.7$ \\
\hline Distal margin & $8.2 \pm 1.1$ \\
\hline \multicolumn{2}{|l|}{ Borrmann type (\%) } \\
\hline II & $32(38.1 \%)$ \\
\hline III & $46(54.8 \%)$ \\
\hline IV & $6(7.1 \%)$ \\
\hline \multicolumn{2}{|l|}{ Tumor location (\%) } \\
\hline $\mathrm{U}$ & $19(22.6 \%)$ \\
\hline M & $32(38.1 \%)$ \\
\hline $\mathrm{L}$ & $33(39.3 \%)$ \\
\hline \multicolumn{2}{|l|}{ Histological type (\%) } \\
\hline Well and/or moderately differentiated & $38(45.2 \%)$ \\
\hline Poorly differentiated and/or undifferentiated & $46(54.8 \%)$ \\
\hline \multicolumn{2}{|l|}{ Lymphatic invasion (\%) } \\
\hline Yes & $33(39.3)$ \\
\hline No & $51(60.7)$ \\
\hline \multicolumn{2}{|l|}{ Vascular invasion (\%) } \\
\hline Yes & $30(35.7)$ \\
\hline No & $54(64.3)$ \\
\hline \multicolumn{2}{|l|}{ Postoperative complications (\%) } \\
\hline Yes & $6(7.1)$ \\
\hline No & $78(92.9)$ \\
\hline \multicolumn{2}{|l|}{ Postoperative chemotherapy (\%) } \\
\hline Yes & $44(52.4 \%)$ \\
\hline No & $40(47.6 \%)$ \\
\hline
\end{tabular}

\section{Short-Term Outcomes and Postoperative Complications}

Totally, 6 patients (7.1\%) developed postoperative complications which identified within 30 days after operation and 3 cases developed more than one type. There was one duodenal stump leakage, one gastro-jejun anastomotic leakage, 3 of intestinal obstruction, 2 of postoperative anastomotic bleeding and wound infection were observed in 4 cases. There was no death during hospitalization. Data are provided in Table 2.

Table 2: Postoperative Complications.

\begin{tabular}{|c|c|}
\hline Variables & $\mathbf{N}(\%)$ \\
\hline Duodenal stump leakage & $1(1.2)$ \\
\hline Gastro-jejun anastomotic leakage & $1(1.2)$ \\
\hline Intestinal obstruction & $3(3.6)$ \\
\hline Anastomotic bleeding & $2(2.4)$ \\
\hline Wound infection & $4(4.8)$ \\
\hline
\end{tabular}

\section{Long-Term Outcomes and Prognostic Factors}

The follow-up periods ranged from 14 to 81 months, and the median follow-up period was 40 months. The 1, 3 and 5-year overall survival rates were $83.9 \%, 67.0 \%$ and $39.2 \%$, respectively.
Univariate analysis showed following variables had no relation to OS: age, sex, BMI, the preoperative level of hemoglobin, platelet and albumin, tumor size, operation procedure, tumor location, resection margin, number of lymph node dissection and postoperative complications. The higher level of carcinoembryonic antigen (CEA, $p=0.011$ ), poorly differentiated pathological classification $(\mathrm{p}=0.023)$, tumor with Borrmann type IV ( $\mathrm{p}=0.005)$, without postoperative chemotherapy ( $p=0.039)$, the presence of lymphatic and vascular invasion $(\mathrm{p}<0.001)$ were found associated with impaired OS. Multivariate analysis of the above variables revealed that the level of CEA and the presence of lymphatic invasion were the only independent prognostic factors for OS. Data are provided in (Tables 3 \& 4). The survival curves of patients according to the independent prognostic factors are presented in (Figures $1 \& 2$ ).

Table 3: Univariate analysis of prognostic factors affecting survival in patients with pT4aN0M0 gastric cancer.

\begin{tabular}{|c|c|c|c|}
\hline Variables & N (\%) & $\begin{array}{c}\text { 3-year survival } \\
\text { rate (\%) }\end{array}$ & $\mathbf{p}$ \\
\hline Mean age (years) & & & 0.061 \\
\hline$\leq 70$ & $34(40.5)$ & 46.9 & \\
\hline$>70$ & $50(59.5)$ & 62.5 & \\
\hline Sex & & & 0.577 \\
\hline Male & $53(63.1)$ & 57.4 & \\
\hline Female & $31(36.9)$ & 47 & \\
\hline BMI & & & 0.17 \\
\hline$\leq 21$ & $33(39.3)$ & 61 & \\
\hline$>21$ & $51(60.7)$ & 87.2 & \\
\hline Hemoglobin (g/L) & & & 0.431 \\
\hline$\leq 120$ & $46(54.8)$ & 57.6 & \\
\hline$>120$ & $38(45.2)$ & 65.5 & \\
\hline Platelet $\left(\times 10^{\wedge} 9 / \mathrm{L}\right)$ & & & 0.219 \\
\hline$\leq 100$ & $18(21.4)$ & 61.2 & \\
\hline$>100$ & $66(78.6)$ & 69.4 & \\
\hline Albumin (g/L) & & & 0.119 \\
\hline$\leq 35$ & $34(40.5)$ & 68.2 & \\
\hline$>35$ & $50(59.5)$ & 61 & \\
\hline CEA (ng/ml) & & & 0.011 \\
\hline$\leq 15$ & $75(89.3)$ & 65.7 & \\
\hline$>15$ & $9(10.7)$ & 20 & \\
\hline Tumor size $(\mathrm{cm})$ & & & 0.159 \\
\hline$\leq 4$ & $28(33.3)$ & 69.6 & \\
\hline$>4$ & $56(66.7)$ & 44.1 & \\
\hline Laparoscopic surgery & & & 0.127 \\
\hline Yes & $73(86.9)$ & 54.5 & \\
\hline NO & $11(13.1)$ & 61.9 & \\
\hline Type of gastrectomy & & & 0.213 \\
\hline
\end{tabular}




\begin{tabular}{|c|c|c|c|}
\hline Total gastrectomy & $40(47.6)$ & 57 & \\
\hline Distal gastrectomy & $44(52.4)$ & 65.5 & \\
\hline $\begin{array}{l}\text { Number of lymph node } \\
\text { dissection }\end{array}$ & & & 0.055 \\
\hline$\leq 20$ & $56(66.6)$ & 43.6 & \\
\hline$>20$ & $28(33.4)$ & 59.9 & \\
\hline Operative time (min) & & & 0.218 \\
\hline$\leq 240$ & 33 (39.3) & 59.2 & \\
\hline$>240$ & $51(60.7)$ & 58.1 & \\
\hline $\begin{array}{l}\text { Intraoperative blood } \\
\text { loss (ml) }\end{array}$ & & & 0.318 \\
\hline$\leq 100$ & $22(26.2)$ & 64.2 & \\
\hline$>100$ & $62(73.8)$ & 49.8 & \\
\hline $\begin{array}{l}\text { Distance of resection } \\
\text { margin }(\mathrm{cm})\end{array}$ & & & \\
\hline Proximal margin, & & & 0.438 \\
\hline$\leq 5$ & $54(64.3)$ & 63 & \\
\hline$>5$ & $30(35.7)$ & 55.5 & \\
\hline Distal margin & & & 0.117 \\
\hline$\leq 5$ & 17 (20.2) & 47.5 & \\
\hline$>5$ & $67(79.8)$ & 58.7 & \\
\hline Borrmann type & & & 0.005 \\
\hline II & $32(38.1 \%)$ & 72.4 & \\
\hline III & $46(54.8 \%)$ & 70.6 & \\
\hline IV & $6(7.1 \%)$ & 16.7 & \\
\hline Tumor location & & & 0.151 \\
\hline U & $19(22.6 \%)$ & 68.7 & \\
\hline M & $32(38.1 \%)$ & 61.3 & \\
\hline $\mathrm{L}$ & $33(39.3 \%)$ & 74.7 & \\
\hline Histological type & & & 0.023 \\
\hline $\begin{array}{l}\text { Well and/or moderate- } \\
\text { ly differentiated }\end{array}$ & $38(45.2 \%)$ & 83.7 & \\
\hline $\begin{array}{l}\text { Poorly differentiated } \\
\text { and/or undifferenti- } \\
\text { ated }\end{array}$ & $46(54.8 \%)$ & 33.6 & \\
\hline Lymphatic invasion & & & $<0.001$ \\
\hline Yes & 33 (39.3) & 45.4 & \\
\hline No & $51(60.7)$ & 81.4 & \\
\hline \multicolumn{4}{|l|}{ Vascular invasion } \\
\hline Yes & $30(35.7)$ & 41 & $<0.001$ \\
\hline No & $54(64.3)$ & 84.1 & \\
\hline $\begin{array}{l}\text { Postoperative compli- } \\
\text { cations }\end{array}$ & & & 0.209 \\
\hline Yes & $6(7.1)$ & 72.7 & \\
\hline No & $78(92.9)$ & 70.8 & \\
\hline $\begin{array}{c}\text { Postoperative chemo- } \\
\text { therapy }\end{array}$ & & & 0.039 \\
\hline Yes & $44(52.4 \%)$ & 76.7 & \\
\hline No & $40(47.6 \%)$ & 55.2 & \\
\hline
\end{tabular}

Table 4: Multivariate analysis of prognostic factors.

\begin{tabular}{|c|c|c|c|}
\hline Variables & HR & $\mathbf{9 5 \% C I}$ & $\mathbf{p}$ \\
\hline CEA & 0.221 & $0.102-0.480$ & $<0.001$ \\
\hline Pathological classification & 1.33 & $0.729-2.424$ & 0.353 \\
\hline Borrmann type IV & 1.07 & $0.678-1.690$ & 0.771 \\
\hline Lymphatic invasion & 0.417 & $0.549-1.384$ & $<0.001$ \\
\hline Vascular invasion & 0.75 & $0.370-1.524$ & 0.427 \\
\hline Postoperative chemotherapy & 1.49 & $0.846-2.624$ & 0.167 \\
\hline
\end{tabular}

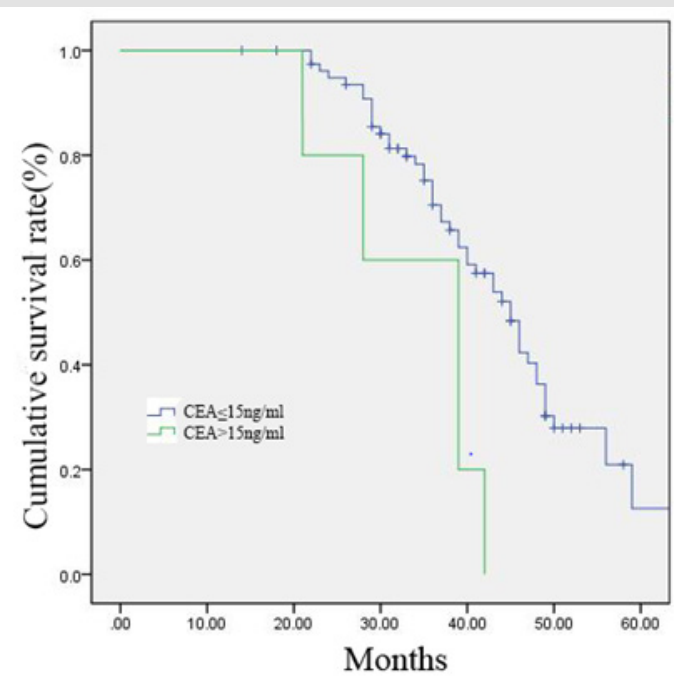

Figure 1: 84 gastric cancer patients were divided into two groups according to the serum level of CEA $(\leq 15 \mathrm{ng} / \mathrm{ml}$ group, $\mathrm{n}=75 ;>15 \mathrm{ng} / \mathrm{ml}$ group, $\mathrm{n}=9$ ). Survival curves were generated by the Kaplan-Meier method.

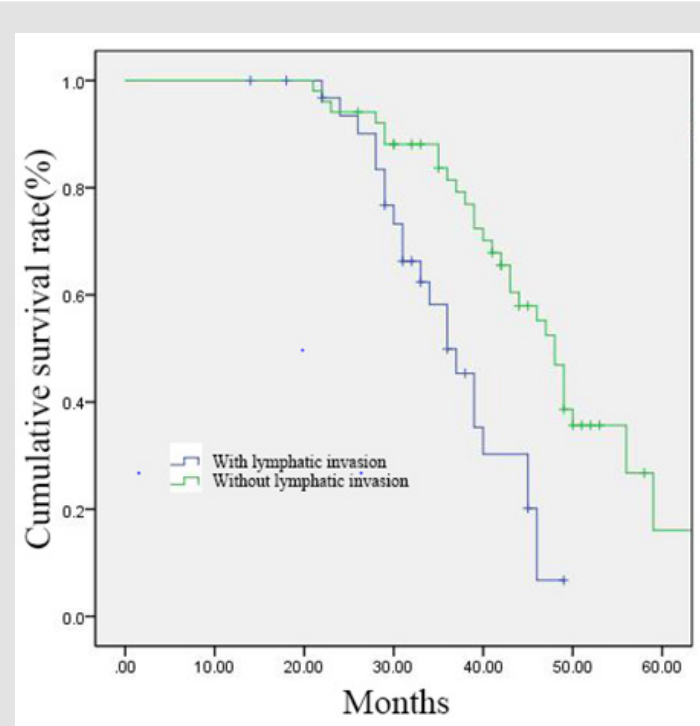

Figure 2: 84 gastric cancer patients were divided into two groups according to the presence of lymphatic invasion (with lymphatic invasion group, $\mathrm{n}=33$; without lymphatic invasion group, $n=51$ ). Survival curves were generated by the Kaplan-Meier method. 


\section{Discussion}

Although lymph node metastases are confirmed as one of the most significant predictors of postoperative outcome for gastric cancer patients, it does not suggest node-negative patients have no chance of recurrence [12-14].Researchers have reported that the depth of tumor invasion was an independent predictor related to the postoperative survival rate, which is independent of lymph node metastasis [15]. pT4aN0M0 stage gastric cancer means that tumor cells have invaded the serosal and there is no evidence of lymph node metastasis or distant metastasis. Its special characteristics are summarized as follows: Compared with the early gastric cancer without lymph node metastasis, the risk of metastasis of peritoneal implantation is large. However, compared with the pT4a stage patients with lymph node metastasis the postoperative long-term outcomes have obvious advantages.

The 5-year OS in node-negative gastric cancer patients after radical surgical cure varied from $72 \%$ to $97.1 \%$ in node-negative patients according to the reports [16-18]. In the present study, we evaluated 84 patients with pT4aN0M0 gastric cancer who underwent curative gastrostomy combined with D2 or D2+ lymph node dissection at a single institution. The 1, 3 and 5-year overall survival rates were $83.9 \%, 67.0 \%$ and $39.2 \%$, respectively, and the surgical morbidity was $7.1 \%$ in this study, which is significantly worse than node-negative patients with early $\mathrm{T}$ stage. Thus, identifying high-risk factors for the recurrence of patients with pT4aN0M gastric cancer who underwent radical surgical treatment help to distinguish high-risk patients and to provide individualized postoperative therapy.

The prognosis of gastric cancer patients with node-negative examined by routine detection methods could be aggravated by lymph node micrometastasis which is related to advanced $\mathrm{T}$ stage [19-20]. In the present investigation, although lymph node micrometastasis is not routinely tested, we found the presence of lymphatic invasion were significantly associated with an impaired OS for pT4a patients with node negative. As the previous reports suggest that, harvesting more nodes may not have therapeutic benefit in early gastric cancer. However, in advanced stages, large number of nodes to be removed is necessary because of the potential micrometastasis. In our study, univariate analysis showed no relation between OS and the number of lymph node dissection may because of the patients selected all underwent extended lymphadenectomy with an average of 25.4 lymph nodes resection.

We also found that he higher serum level of CEA was a negative predictor, patients with lower levels preoperatively had a longer OS than those patients with higher levels. CEA is a glycoprotein with a weight of $200 \mathrm{kDa}$, which play an important role in programmed cell death adhesion in mammals. It is one of the most common tumor markers which is widely using in cancer diagnosis and treatment decision especially in gastrointestinal cancer [21-23]. However, the value of serum level of CEA for postoperative surveillance remains poorly understood. We revealed that a high preoperative serum CEA level was independently associated with a poor prognosis after radical gastrectomy in patients with no lymph node metastases. This finding may reflect a widely accepted hypothesis that the long-term outcome of cancer patients is not determined by tumor characteristics alone, but also associated with cancer-related microenvironment.

\section{Conclusion}

Although this study had limitations, the investigation demonstrated that the higher serum level of CEA and the presence of lymphatic invasion were associated with an unfavorable oS for patients with pT4aN0M0 gastric cancer who underwent curative gastrostomy combined with D2 or D2+ lymph node dissection. Such patients should be considered to provide individual follow-up and adjuvant therapy because of an increased risk of postoperative recurrence.

\section{Acknowledgements}

This research received no specific grant funding from any funding agency in the public, commercial, or not-for-profit sectors.

\section{Conflict of Interest}

The authors declared no potential conflicts of interest with respect to the research, authorship and/or publication of this article.

\section{References}

1. Songun I, Putter H, Kranenbarg EMK, Mitsuru Sasako, Cornelis J H van de Velde (2010) Surgical treatment of gastric cancer: 15-year followup results of the randomised nationwide Dutch D1D2 trial. The lancet oncology 11(5): 439-449.

2. Bozzetti F, Marubini E, Bonfanti G, Rosalba Miceli, Chiara Piano, et al. (1999) Subtotal versus total gastrectomy for gastric cancer: five-year survival rates in a multicenter randomized Italian trial. Annals of surgery $230(2): 170-178$

3. Wong R, Cunningham D (2009) Optimising treatment regimens for the management of advanced gastric cancer. Ann Oncol. 20(4): 605-608.

4. Jiang L, Yang K H, Chen Y, Q L Guan, P Zhao, et al. (2014) Systematic review and meta-analysis of the effectiveness and safety of extended lymphadenectomy in patients with resectable gastric cancer. British Journal of Surgery 101(6): 595-604.

5. Lui SA, Tan WB, Tai BC, Wei Peng Yong, Yar Soe Mu, et al. (2019) Predictors of survival outcome following radical gastrectomy for gastric cancer. ANZ J Surg 89(1-2): 84-89.

6. Schwarz RE, Zagala-Nevarez K (2002) Recurrence patterns after radical gastrectomy for gastric cancer: prognostic factors and implications for postoperative adjuvant therapy. Ann Surg Oncol 9(4): 394-400.

7. Kim JH, Jang YJ, Park SS, Seung-Joo Kim, Young-Jae Mok, et al. (2009) Surgical outcomes and prognostic factors for T4 gastric cancers. Asian J Surg 32(4): 198-204.

8. Shchepotin IB, Chorny VA, Nauta RJ, M Shabahang, R R Buras, et al. (1998) Extended surgical resection in T4 gastric cancer. Am J Surg 175(2): 123-126. 
9. Chou HH, Kuo CJ, Hsu JT, Tsung-Hsing Chen, Chun-Jun Lin, et al. (2013) Clinicopathologic study of node-negative advanced gastric cancer and analysis of factors predicting its recurrence and prognosis. Am J Surg 205(6): 623-630.

10. Qiu MZ, Wang ZQ Luo HY, Dong-sheng Zhang, Zhi-wei Zhou, et al. (2011) Prognostic analysis in node-negative gastric cancer patients in China. Tumor boil 32(3): 489-492.

11. Edge SB, Compton CC (2010) The American Joint Committee on Cancer: the $7^{\text {th }}$ edition of the AJCC cancer staging manual and the future of TNM. Ann Surg Oncol 17(6): 1471-1474.

12. Qiang Xue, Xiao-Na Wang, Jing-Yu Deng, Ru-Peng Zhang,Han Liang (2013) Effects of extended lymphadenectomy and postoperative chemotherapy on node-negative gastric cancer. World J Gastroenterol 19(33): 55515556.

13. Xu-Guang Jiao, Jing-Yu Deng, Ru-Peng, Liang-Liang Wu, Li Wang, et al. (2014) Prognostic value of number of examined lymph nodes in patients with node-negative gastric cancer. World J Gastroenterol 20(13): 36403648.

14. Lin-Yong Zhao, Xiao-Long Chen, Yi-Gao Wang, Yue Xin, Wei-Han Zhang, et al. (2016) A new predictive model combined of tumor size, lymph nodes count and lymphovascular invasion for survival prognosis in patients with lymph node-negative gastric cancer. Oncotarget 7(44): 7230072310 .

15. Jingyu Deng, Han Liang, Dan Sun, Rupeng Zhang, Hongjie Zhan, et al. (2008) Prognosis of gastric cancer patients with node-negative metastasis following curative resection: Outcomes of the survival and recurrence. Can J Gastroenterol 22(10): 835-839.

ISSN: $2574-1241$

DOI: $10.26717 /$ BJSTR.2020.28.004683

Li Wei. Biomed J Sci \& Tech Res

(C) This work is licensed under Creative Commons Attribution 4.0 License

Submission Link: https://biomedres.us/submit-manuscript.php
16. Bruno L, Nesi G, Montinaro F, G Carassale, V Boddi, et al. (2000) Clinicopathologic characteristics and outcome indicators in nodenegative gastric cancer. J Surg Oncol 74(1): 30-32.

17. Lee CC, Wu CW, Lo SS, Jen-Hao Chen, Anna F-Y Li, et al. (2007) Survival predictors in patients with node-negative gastric carcinoma. J Gastroenterol Hepatol 22(7): 1014-1018.

18. Liu C, Zhang R, Lu Y, Hua Li, Ping Lu, et al. (2010) Prognostic role of lymphatic vessel invasion in early gastric cancer: A retrospective study of 188 cases. Surg Oncol 19(1): 4-10.

19. Kikuchi Y, Tsuchiya A, Ando Y, Tsuneyuki Yoshida, Seiichi Takenosita (1999) Immunohistochemical detection of lymphnode microinvolvement in node-negative gastric cancer. Gastric Cancer 2(3): 173-178.

20. Matsumoto M, Natsugoe S, Ishigami S, Akihiro Nakajo, Futoshi Miyazono, et al. (2002) Lymph node micrometastasis and lymphatic mapping determined by reverse transcriptase-polymerase chain reaction in $\mathrm{pN} 0$ gastric carcinoma. Surgery 131(6): 630-635.

21. Chao-Zhu He, Kun-He Zhang, Qing Li, Xiao-Hua Liu, Yan Hong, et al. (2013) Combined use of AFP, CEA, CA125 and CAl9-9 improves the sensitivity for the diagnosis of gastric cancer BMC Gastroenterol 13: 87.

22. Zhipeng Sun, Nengwei Zhang (2014) Clinical evaluation of CEA, CA199, CA72-4 and CA125 in gastric cancer patients with neoadjuvant chemotherapy. World J Surg Oncol 12: 397.

23. Marta Łukaszewicz-Zając, Barbara Mroczko, Mariusz Gryko, Bogusław Kędra, Maciej Szmitkowski (2011) Comparison between clinical significance of serum proinflammatory proteins (IL-6 and CRP) and classic tumor markers (CEA and CA 19-9) in gastric cancer. Clin Exp Med 11(2): 89-96.

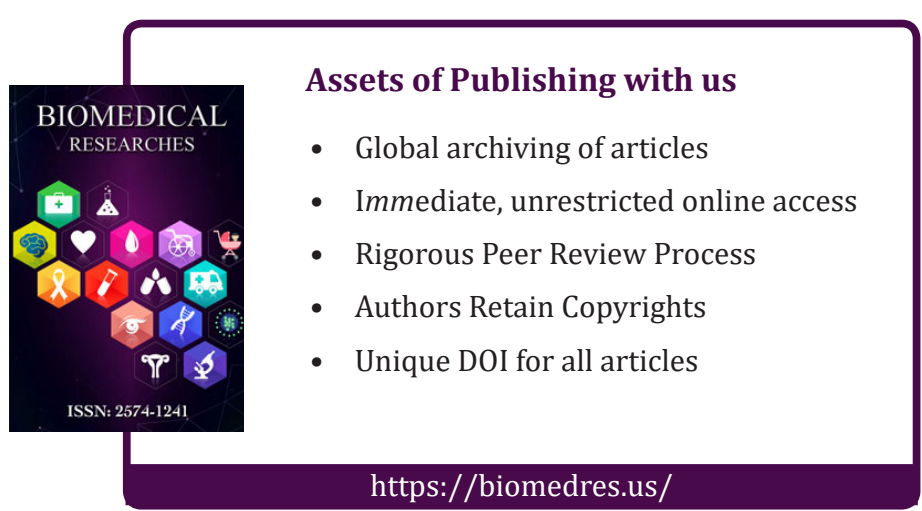

